06

\title{
Исследование микроструктуры композиционного материала на основе алюминия с добавлением углеродных нанотрубок после искро-плазменного спекания
}

\author{
(C) Н.А. Бунаков, Д.В. Козлов, В.Н. Голованов
}

Ульяновский государственный университет, Научно-исследовательский технологический институт им. С.П. Капицы, 432017 Ульяновск, Россия

e-mail: na_bunakov@mail.ru

(Поступило в Редакцию 19 января 2018 г.)

\begin{abstract}
Методами электронной микроскопии проведены исследования образцов алюмоматричного композиционного материала с многостенными углеродными нанотрубками (МУНТ). Выявлены особенности изменений микроструктуры, происходящих при получении композита в установке искро-плазменного спекания (ИПС). Представлены результаты моделирования процесса ИПС с учетом высоких электро- и теплопроводящих свойств МУНТ, качественно объясняющие различия процессов спекания образцов чистого алюминия и композита.
\end{abstract}

DOI: $10.21883 / J T F .2018 .12 .46785 .29-18$

\section{Введение}

Одним из основных путей создания новых высокопрочных материалов является получение композитов, для которых необходимое сочетание эксплуатационных свойств может быть подобрано на стадии разработки материала. При этом современные экспериментальные и теоретические методы исследований позволяют целенаправленно использовать компоненты в виде микро- и наноразмерных элементов.

Среди наноразмерных упрочнителей особое место занимают многостенные углеродные нанотрубки (МУНТ). Их уникальные свойства [1] могут служить основой для разработки материалов, сочетающих целый ряд необычных (для одного материала) физико-механических свойств, таких как высокая удельная прочность, анизотропная тепло- и электропроводность и т. П. При этом во многих исследованиях показано, что даже небольшие (0.01-1\%) добавки МУНТ могут существенно изменять свойства исходных материалов. В настоящей работе рассматриваются способ получения и свойства композиционного материала, представляющего собой смесь алюминия и МУНТ.

Наиболее доступным способом получения композитов Al-МУНТ, при котором возможно достижение необходимой однородности смеси, является использование приемов порошковой металлургии [2]. Металл в виде частиц микронных размеров перемешивается с МУНТ, и смесь спекается под давлением с образованием алюминиевой матрицы, армированной углеродными нанотрубками. Спекание порошков может проводиться различными методами, но перспективным и эффективным способом в настоящее время является метод искро-плазменного спекания (ИПС). ИПС является менее энергозатратным методом для получения высокоплотных композитов, в то время как при обычном спекании и горячем прессовании для достижения необходимой плотности и свойств требуются, как правило, большое давление прессования, длительная выдержка и дополнительные деформационные обработки [3].

При этом исходное состояние поверхности частиц порошка Al (толщина и структура оксидных пленок), форма самих частиц порошка, их размеры, присутствие в порошке металла нанотрубок с высокими анизотропными свойствами могут существенно влиять на характер процессов спекания, формирование микроструктуры и окончательные свойства материала.

Целью настоящей работы являлось исследование микроструктурных изменений в композите на основе алюминиевой матрицы при добавлении МУНТ в процессе ИПС.

\section{1. Материалы и методика эксперимента}

В качестве исходных материалов использовался порошок алюминия марки ПАД-6* чистотой не менее $99.4 \%$, размером $\sim 2-6 \mu \mathrm{m}$ (производство ООО „ВАЛКОМ-ПМ“) и МУНТ (содержание аморфного углерода и графита не более $2 \%$ ), полученные методом MOCVD [2], и функционализированные в смеси концентрированных серной и азотной кислот [4].

Получение равномерного распределения функционализированных нанотрубок (ФМУНТ) в порошке алюминия проводилось путем смешивания дисперсий исходных материалов в этаноле под воздействием ультразвука (У3) с последующей сушкой [5].

Консолидация высушенных порошков выполнялась путем ИПС в вакууме при $600^{\circ} \mathrm{C}$ со скоростью нагрева $40^{\circ} \mathrm{C} / \mathrm{min}$ и давлении прессования $50 \mathrm{MPa}$. В эксперименте использовался импульсный постоянный ток, 
подаваемый группами из 12 импульсов, за которыми следовало 2 периода отключения. Длительность импульса составляла $3 \mathrm{~ms}$, время отключения $2 \mathrm{~ms}$.

Таким образом, были подготовлены композиты с содержанием $0.5 \mathrm{wt} \%$ функционализированных МУНТ (ФМУНТ) с временем спекания $\left(t_{s}\right) 5,20$ и $40 \mathrm{~min}$, и контрольный образец чистого алюминия $\left(t_{s}=20 \mathrm{~min}\right)$.

Плотность композитов измерялась методом гидростатического взвешивания.

Структура композитных смесей и компактных образцов исследовалась на сканирующем электронном микроскопе (СЭМ) PHENOM ProX. В связи с высокой вязкостью чистого алюминия после полировки образцы слегка протравливались для снятия поверхностного сильнодеформированного слоя.

Высокоразрешающее исследование микроструктуры проводилось на просвечивающем электронном микроскопе (ПЭМ) FEI Tecnai G2 с ускоряющим напряжением $200 \mathrm{kV}$. Образцы для ПЭМ механически утонялись и ионно полировались на приборе Gatan Model 691c энергией пучка ионов $\mathrm{Ar}^{+}$в $4 \mathrm{keV}$ под углом $6^{\circ}$.

Исследование фазового состава композитов проводилось на приборе комбинационного рассеяния света (KPC) Renishaw InVia.

Моделирование процесса ИПС проводилось методом конечных элементов в среде Comsol Multiphysics.

\section{2. Микроструктура и свойства АІ-ФМУНТ после ИПС}

С учетом результатов гранулометрического анализа и наличия на поверхности частиц оксидной пленки толщиной $25 \mathrm{~nm}$ расчетная плотность спеченного алюминиевого порошка составила $2.74 \mathrm{~g} / \mathrm{cm}^{3}$ [6].

Относительные плотности полученных образцов после спекания приведены в табл. 1 .

При СЭМ исследовании образца алюминия без МУНТ (контрольного образца) обнаруживаются равномерно распределенные поры размером 300-700 nm (рис. 1,a).

При анализе микроструктуры контрольного образца на ПЭМ прослеживаются зерна с четкой границей раздела. Размер зерен в большей степени лежит в пределах от 1 до $6 \mu \mathrm{m}$, что соответствует размеру исходных частиц порошка (рис. 1,b). Оксидная пленка претерпевает

Таблица 1. Относительные плотности полученных композитов в зависимости от времени спекания

\begin{tabular}{c|c|c}
\hline Образец & $\begin{array}{c}\text { Время спекания } \\
\left(t_{s}\right), \text { min }\end{array}$ & $\begin{array}{c}\text { Относительная } \\
\text { плотность, } \%\left(\mathrm{~g} / \mathrm{cm}^{3}\right)\end{array}$ \\
\hline $\begin{array}{c}\text { Контрольный образец } \\
\text { (А1 без ФМУНТ) }\end{array}$ & 20 & 98.38 \\
Al-0.5 wt.\% ФМУНТ & 5 & 97.74 \\
Al-0.5 wt.\% ФМУНТ & 20 & 98.20 \\
Al-0.5 wt.\% ФМУНТ & 40 & 98.42
\end{tabular}

разрушение в процессе спекания на фрагменты с характерным размером 20-30 nm, которые преимущественно сосредоточены по границам зерен (исходных частиц) алюминия (рис. 1, $c$ ).

Для композита Al-0.5wt.\% ФМУНТ в зависимости от времени выдержки при ИПС видно, что добавление нанотрубок существенно влияет на процесс спекания (рис. 2). По результатам СЭМ структура композита $t_{s}=5$ min. имеет незначительное количество спеченных зон (рис. 2,a), каждая частица алюминия преимущественно ограничена „темными“ областями толщиной до $300 \mathrm{~nm}$.

Сравнивая микроструктуры контрольного образца и композита, полученных при одинаковом времени спекания $\left(t_{s}=20 \mathrm{~min}\right)$, видно, что введение нанотрубок приводит к худшей спекаемости и увеличению протяженности и размера пустот между частицами алюминия (рис. 2, $b$ ).

С увеличением времени спекания протяженность пустот по границам зерен уменьшается, прослеживается увеличение плотности композита и при $t_{s}=40 \mathrm{~min}$ границы между исходными частицами порошка алюминия исчезают (рис. 2,c). На рис. 2, с видно, что при длительном спекании структура композита по данным СЭМ насыщена большим количеством пор размером, не превышающим $400 \mathrm{~nm}$.

На рис. 3 приведены ПЭМ изображения, демонстрирующие характер спекания алюминиевых частиц в зависимости от времени спекания. Для $t_{s}=5 \mathrm{~min}$ прослеживается преимущественное сохранение оксидной пленки, что препятствует спеканию алюминиевой матрицы (области 2 на рис. $3, a$ ). Соответственно размер и количество характерных зон с межчастичным металлическим контактом незначительны (область 1 на рис. $3, b)$. С увеличением времени спекания количество и размер неспеченных областей уменьшаются (области 2 на рис. $3, b)$, наблюдается все более выраженное разрушение оксидной пленки и перемещение ее фрагментов в глубину зерна на расстояние до 150-200 nm (области 1 на рис. $3, b, c)$. После $40 \mathrm{~min}$ спекания почти все межзеренные границы представляют собой области полного спекания с характерной структурой, изображенной на рис. $3, c$.

Контакт алюминия с нанотрубками, преимущественно расположенными по границам зерен, улучшается по мере увеличения времени спекания. Уменьшается размер несплошностей и количество пор по границам МУНТ. На рис. $4, b$ наблюдается ярко-выраженное разрушение оксидной пленки и образование плотного контакта МУНТ с матрицей. Однако независимо от времени спекания, в структуре композитов остаются области, где взаимодействие компонентов отсутствует (рис. 4, $a$ ).

Встречающиеся ФМУНТ во всех случаях демонстрируют сохранение своей структуры и не претерпевают деструкцию до образования карбидной фазы, что также подтверждалось методом КРС. 

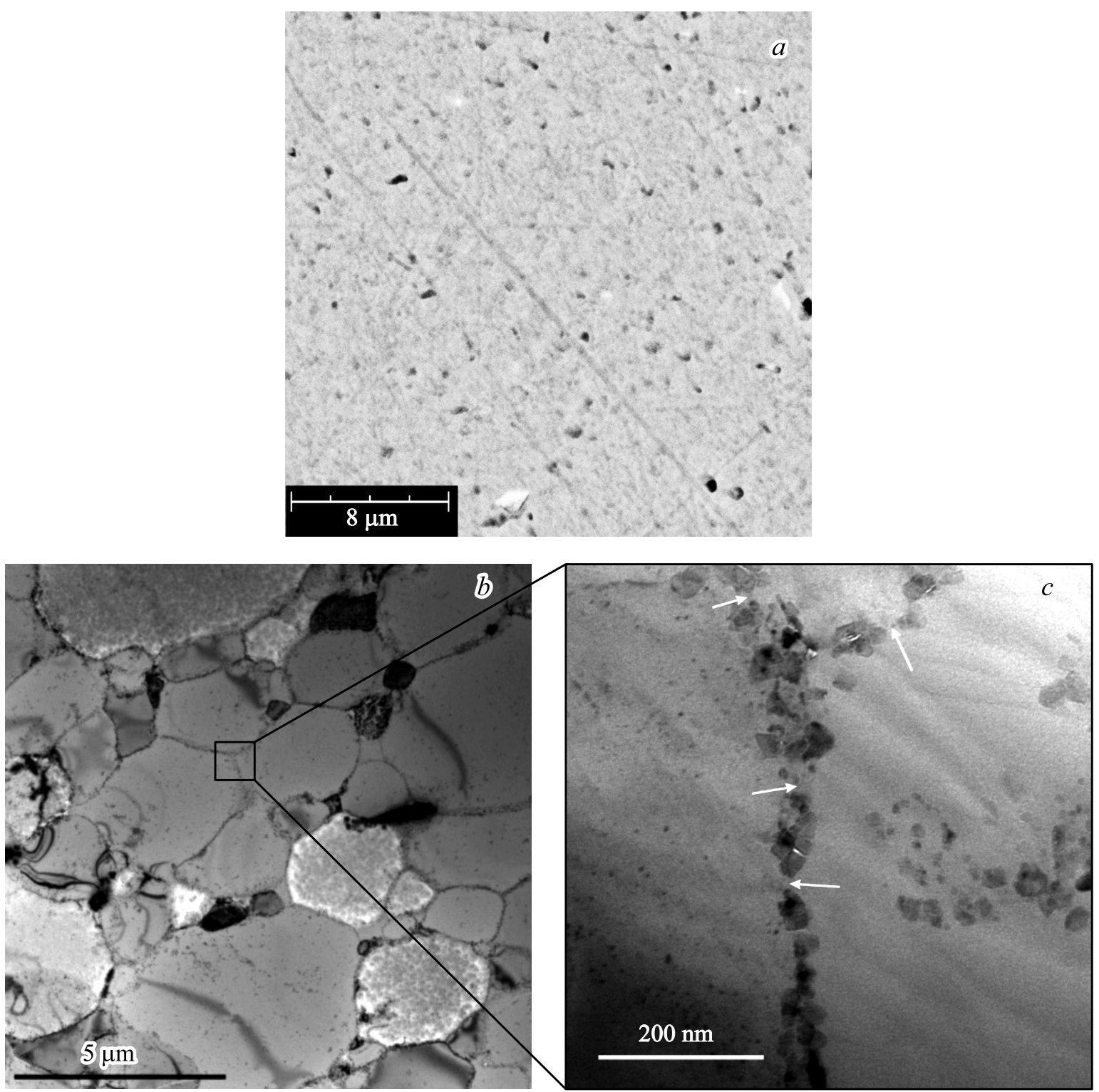

Рис. 1. СЭМ $(a)$ и ПЭМ $(b, c)$ изображения $\mathrm{Al}$ без МУНТ (контрольный образец) после ИПС при $600^{\circ} \mathrm{C}, t_{s}=20 \mathrm{~min}$.

\section{3. Моделирование процесса искро-плазменного спекания}

На основании проведенных микроструктурных исследований и анализа литературных данных при ИПС порошка металла, покрытого оксидной пленкой, происходят следующие процессы.

- На первой стадии при наличии непроводящего оксидного слоя омический контакт между частицами отсутствует, что вызывает накопление электрического заряда на границах раздела частиц порошка. При достижении критического значения напряженности электрического поля между порошинками возникает искровой разряд, что приводит к кратковременным локальным градиентам температуры, которые обеспечивают возникновение термодиффузии, ускоряющей спекание [7].
В разрядном промежутке температура повышается до нескольких десятков тысяч градусов Кельвина, что вызывает мощные термодиффузионные потоки атомов в область контакта частиц и обеспечивает слияние порошинок. Исходя из этого, образующиеся микроэлекрические пробои приводят к очищению поверхности/разрушению оксидного слоя, плавлению материала матрицы и образованию металлических каналов между частицами (зон спекания), что наблюдалось нами на ПЭМ изображениях (области 1 на рис. 3) [3,7-11].

- На второй стадии в области образованных омических контактов дальнейшее образование и рост шейки происходит путем джоулева нагрева [8].

Стоит отметить, что все эти процессы происходят последовательно, но не одновременно во всем объеме материала. 

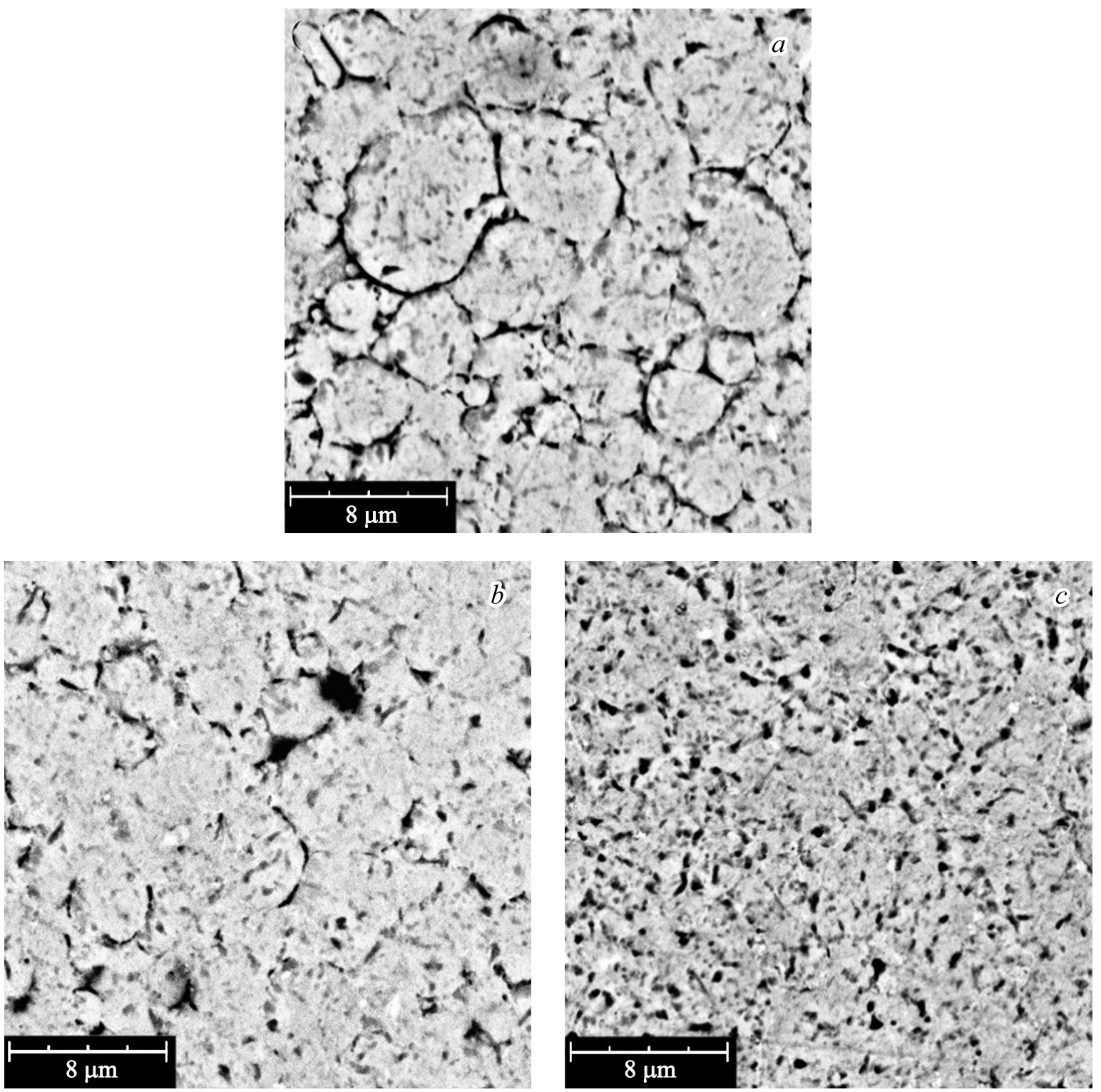

Рис. 2. СЭМ изображения Al-0.5 wt.\% ФМУНТ после ИПС при $600^{\circ} \mathrm{C}, t_{s}: a-5, b-20, c-40 \mathrm{~min}$.

МУНТ, введенные в матрицу, которые, как известно, обладают высокими электро- и теплопроводящими свойствами $[1,12]$, вероятно, могут изменить протекание тока при ИПС и соответственно повлиять на эффективность разрушения оксидной пленки (рис. 5).

С целью описания наблюдаемых микроструктурных особенностей было проведено моделирование протекания тока и тепловыделения в системе из нескольких гранул алюминия с расположенной между ними углеродной нанотрубкой.

\section{1. Описание модели}

Модель представляет собой термодинамически изолированную систему совокупности компонентов композита (частицы алюминия, оксидный слой и углеродная нанотрубка), учитывает протекание через компоненты композита электрического тока, который приводит к нагреву и спеканию частиц и описывается нестационарной системой уравнений, зависящей от времени. Расчетное время составляло $36 \mathrm{~ms}$, соответствующее пакету из 12 импульсов тока. Механическое давление не учитывается. Основными уравнениями задачи являются законы сохранения заряда

$$
\operatorname{div} j=0
$$

и энергии

$$
\rho C_{p} \frac{\partial T}{\partial t}=\operatorname{div}(k \nabla T)+Q_{e},
$$

где $Q_{e}=\mathbf{j} \cdot \mathbf{E}=\sigma E^{2}$ - джоулев нагрев.

В модели рассматривается момент спекания, при котором произошло образование проводящих каналов (металл-металл) в оксидном слое [9-11], без учета 

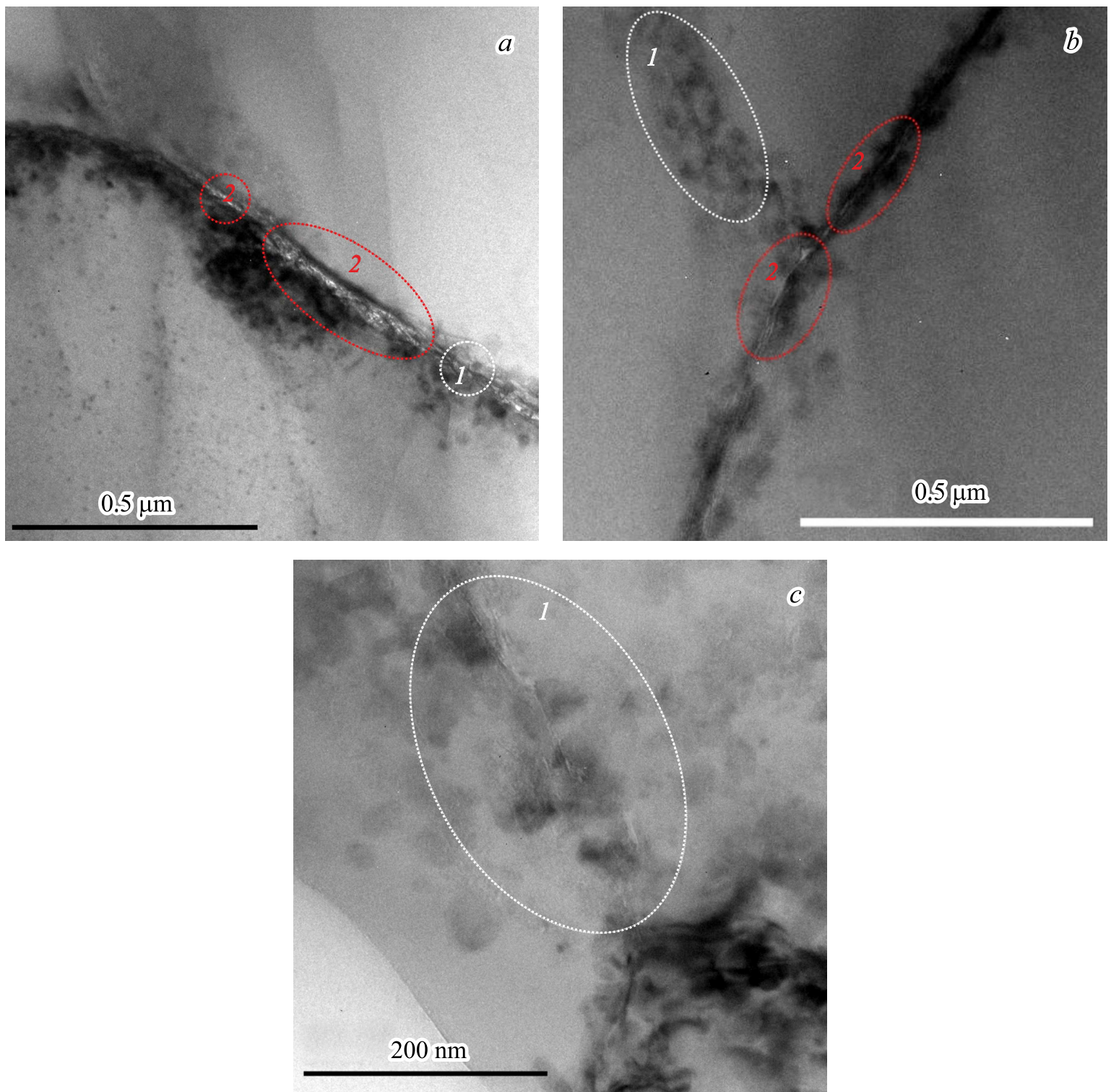

Рис. 3. ПЭМ изображения микроструктур композитов PAl-0.5 wt.\% ФМУНТ (I тип), показывающие характер спекания частиц А, $t_{s}: a-5, b-20, c-40 \mathrm{~min}$.

локального плавления материалов при генерации искрового разряда.

Диаметр алюминиевых частиц был выбран равным $2 \mu \mathrm{m}$, толщина оксидного слоя на поверхности частиц $25 \mathrm{~nm}$ (рис. 6, $a$ ). МУНТ диаметром $d=100 \mathrm{~nm}$ рассматривалась как анизотропный проводник тока и тепла [12]. Выбиралось два случая положения МУНТ относительно направления общего вектора напряженности электрического поля: параллельное (рис. 6, $b$ ) и нормальное (рис. 6, c).

Выбранные свойства материалов модели представлены в табл. 2. Электрическая проводимость оксидного слоя задавалась в виде эффективной проводимости на определенной стадии спекания $(0.03 \mathrm{~S} / \mathrm{m})$, обусловленной наличием проводящих металлических каналов, по данным работ [9-11].
Граничные условия для потенциала и электрического тока задавались следующим образом: нулевой потенциал на нижнем алюминиевом электроде и постоянный ток плотностью $5 \cdot 10^{5} \mathrm{~A} / \mathrm{m}^{2}$ на верхнем электроде (рис. 6). Указанные области, заданные в качестве электродов, в расчетах передачи тепла не участвовали.

\section{2. Результаты моделирования}

В модели, состоящей из групп частиц алюминия без МУНТ, удельная тепловая мощность тока в области оксида составляет $Q_{e}=2.2 \cdot 10^{13} \mathrm{~W} / \mathrm{m}^{3}$.

При добавлении МУНТ происходит падение $Q_{e}$ в области оксидного слоя до значений $0.6 \cdot 10^{13} \mathrm{~W} / \mathrm{m}^{3}$ и $1.2 \cdot 10^{13} \mathrm{~W} / \mathrm{m}^{3}$, так и плотности тока в 2 и 1.5 раза для параллельного и нормального случая соответственно 

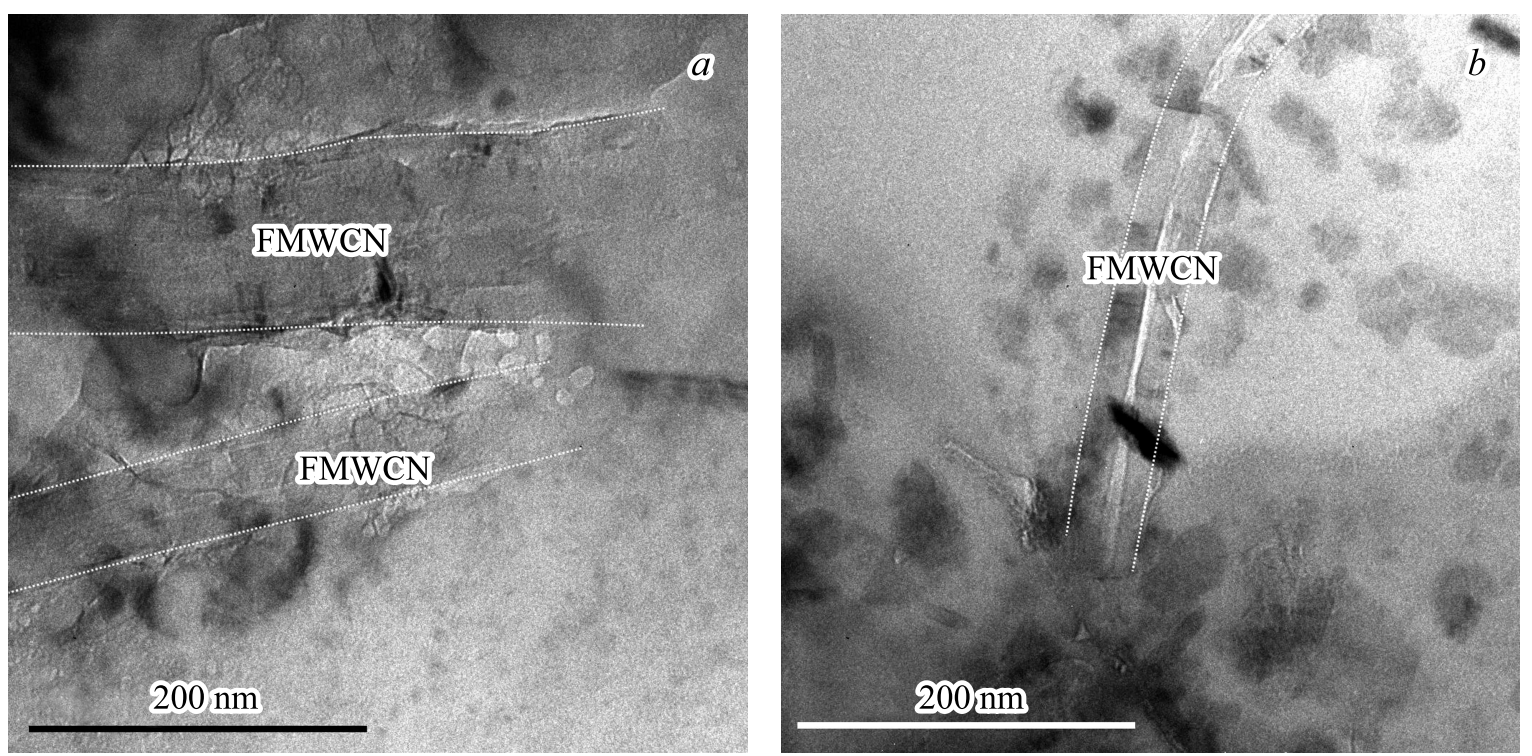

Рис. 4. Виды контактов матрицы с боковой поверхностью ФМУНТ (І тип) при $t_{s}=40$ min: $a-$ контакт преимущественно отсутствует, $b$ - плотный контакт.
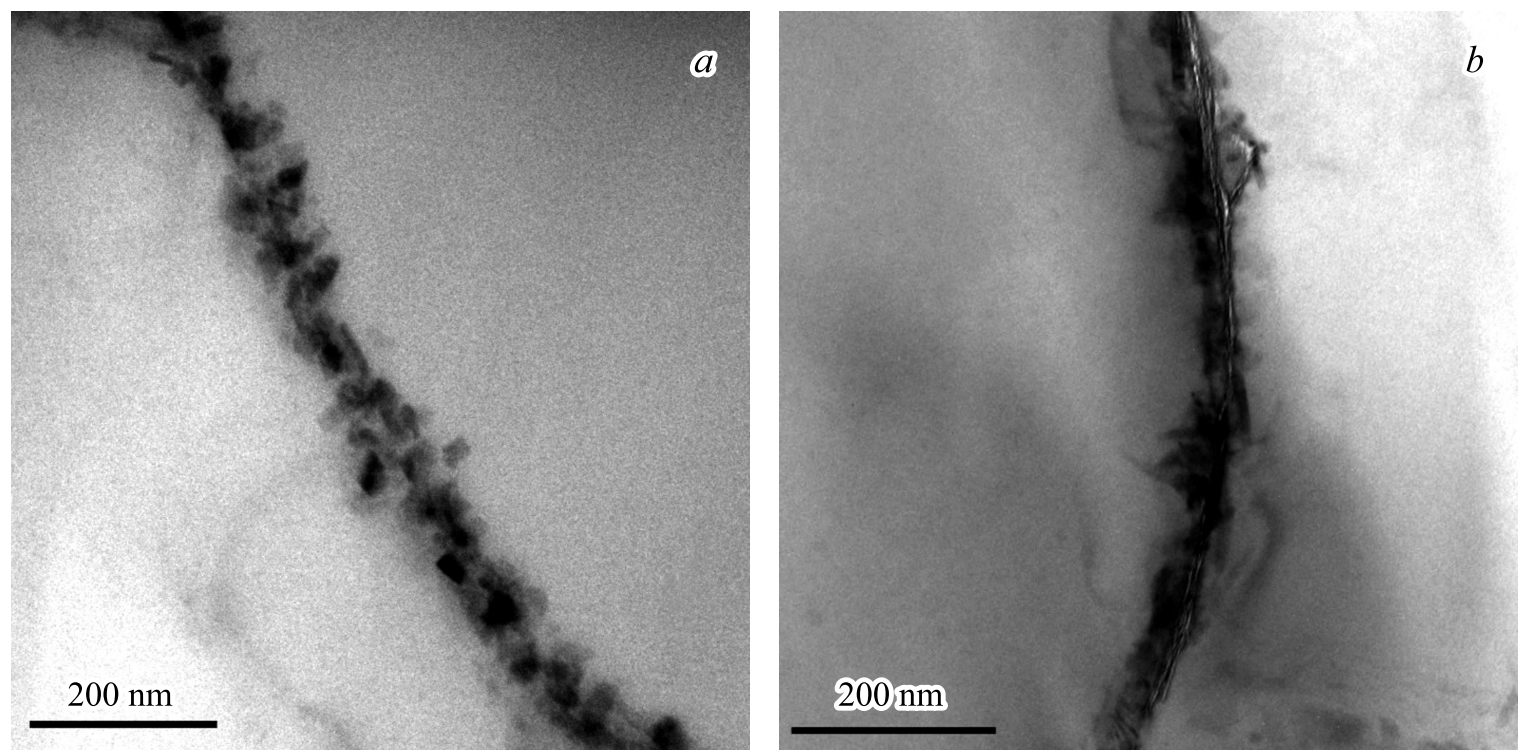

Рис. 5. ПЭМ изображения, демонстрирующие характер разрушения оксидного слоя в: $a-\mathrm{Al}$ без МУНТ (контрольный образец), $b-\mathrm{Al}-0.5 \mathrm{wt} . \%$ МУНT.

Таблица 2. Выбранные свойства материалов

\begin{tabular}{|c|c|c|c|c|}
\hline Параметр & Размерность & $\mathrm{Al}$ & $\mathrm{Al}_{2} \mathrm{O}_{3}$ & МУНТ \\
\hline Теплоемкость, $C_{p}$ & $\mathrm{~J} / \mathrm{kg} \cdot \mathrm{K}$ & 900 & 900 & $700[1,13]$ \\
\hline Теплопроводность, $k$ & $\mathrm{~W} / \mathrm{m} \cdot \mathrm{K}$ & 238 & 27 & $\begin{array}{c}\text { Вдоль оси } 2000 \\
\text { Поперек оси } 8 \text { [12] }\end{array}$ \\
\hline $\begin{array}{c}\text { Электрическая } \\
\text { проводимость, } \sigma\end{array}$ & $\mathrm{cm} / \mathrm{m}$ & $3.774 \cdot 10^{7}$ & $0.03[9-11]$ & $\begin{array}{c}\text { Вдоль оси } 3 \cdot 10^{5} \\
\text { Поперек оси } 0.33 \cdot 10^{3}[12]\end{array}$ \\
\hline Плотность, $\rho$ & $\mathrm{kg} / \mathrm{m}^{3}$ & 2700 & 3900 & $1800[1]$ \\
\hline
\end{tabular}



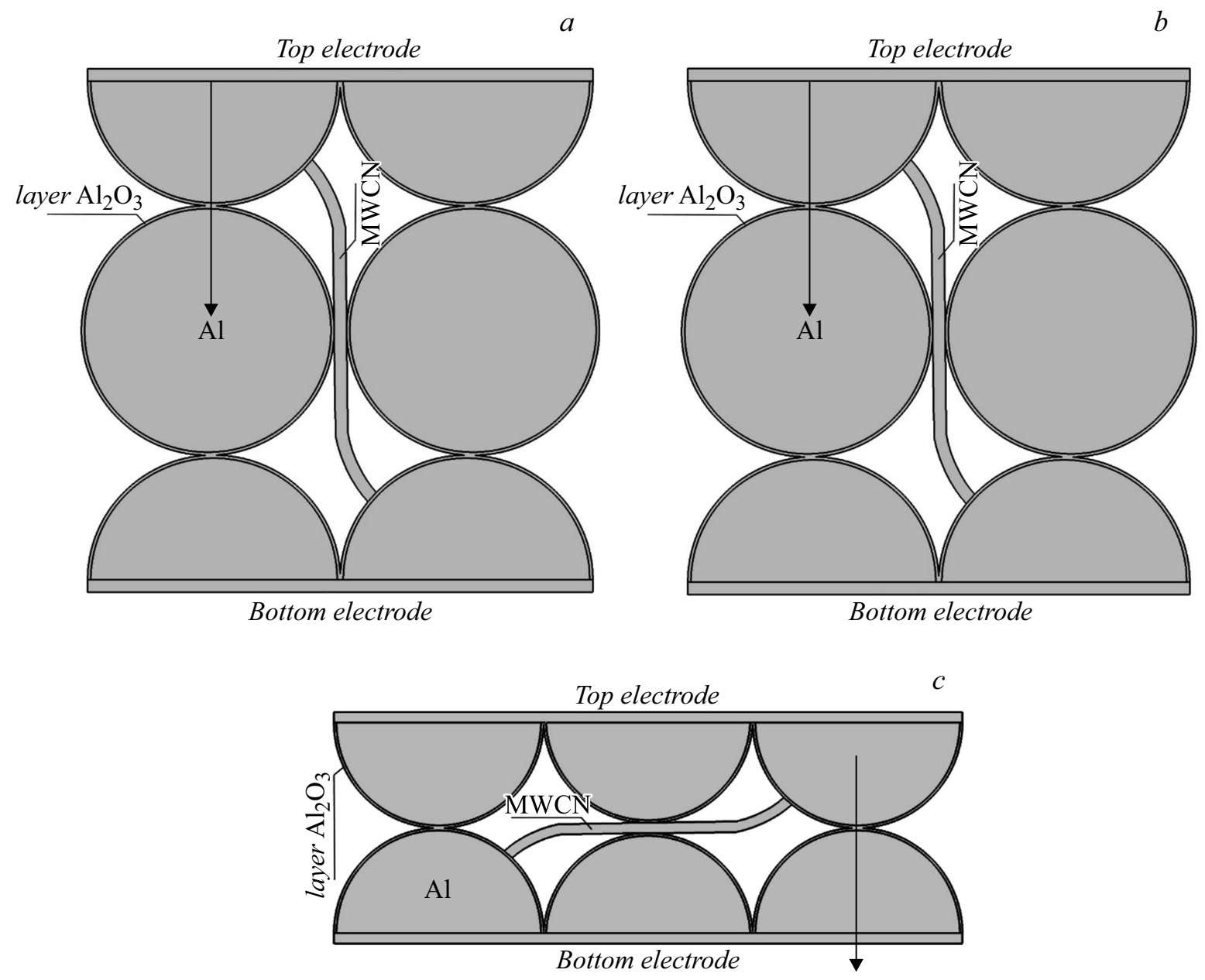

Рис. 6. Схемы групп частиц Al: $a$ - без МУНТ, $b$ - параллельное положение МУНТ, $c$ - нормальное положение МУНТ.

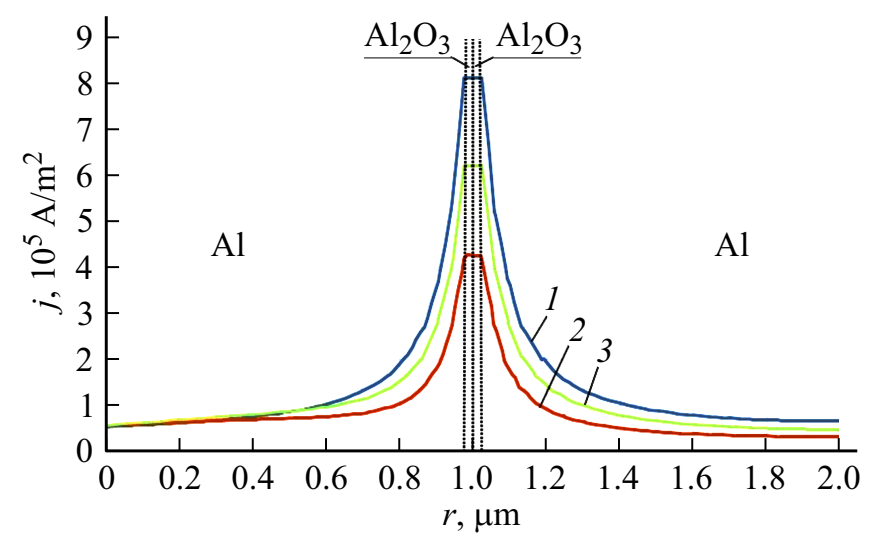

Рис. 7. Графики распределения плотности тока между частицами Al: 1 - без МУНТ, 2 - параллельное положение МУНТ, 3 - нормальное положение МУНТ.

(рис. 7). Графики распределения плотности тока (рис. 7) строились по отмеченным линиям на рис. 6. Поэтому при данных условиях моделирования нагрев частиц алюминия вблизи МУНТ (в том числе и процесс разрушения оксидного слоя) за счет электрического тока будет проходить менее эффективно, что приводит к худшему спеканию частиц металла. Это можно заметить на ПЭМ изображениях (рис. 5).

\section{Заключение}

1) Исследованы изменения микроструктуры образцов чистого алюминия и композита Al-0.5 wt.\% ФМУНТ по мере увеличения времени спекания при температуре $600^{\circ} \mathrm{C}$ и давлении $50 \mathrm{MPa}$. Показано что добавление МУНТ, обладающих высокой тепло- и электропроводностью, замедляет спекание.

2) На основании литературных данных и микроструктурных исследований можно описать процесс спекания в виде следующих стадий:

- разрушение оксидного слоя в искро-плазменном разряде с образованием металлических токопроводящих мостиков между частицами;

- локальное плавление металлических частиц;

- полное спекание частиц с образованием вдоль первоначальных границ слоев толщиной 150-200 nm, 
содержащих частицы разрушенной оксидной пленки и МУНТ.

3) На основе результатов микроструктурных исследований предложена модель процесса тепловыделения в композите, учитывающая свойства алюминиевого порошка и МУНТ. Моделирование показало существенное изменение локального тепловыделения в окрестности углеродных нанотрубок. Эти изменения объясняют различия процессов спекания образцов чистого алюминия и композита.

4) Разработанная модель может быть развита, уточнена и применена для предсказания результатов спекания подобных композитов методом ИПС.

Работа выполнена в рамках государственного задания Минобрнауки России.

\section{Список литературы}

[1] Булярский С.В. Углеродные нанотрубки: технология, управление свойствами, применение. Ульяновск: Стрежень, 2011. 478 с.

[2] Agarwal A., Bakshi S.R., Lahiri D. Carbon nanotubes reinforced metal matrix composites. CRC Press, 2010. 325 p.

[3] Григорьев Е.Г., Калин Б.А. Электроимпульсная технология формирования материалов из порошков. М.: МИФИ, 2008. $152 \mathrm{c}$.

[4] Климов Е.С., Давыдова О.А., Бузаева М.В., Макарова И.А., Козлов Д.В., Бунаков Н.А., Нищев Н.А., Панов А.А., Пыненков А.А. // Башкирский химический журнал. 2014. Т. 21. Вып. 3. С. 109-113.

[5] Бунаков Н.А., Козлов Д.В., Голованов В.Н., Климов Е.С., Ебимов М.С. // Известия вуз. Поволжский регион. 2016. № 2 (38). C. 134-146. DOI: 10.21685/2072-3040-2016-2-11

[6] Kurita H., Miyazaki T., Kawasaki A., Silvain J.-F. // J. Mater. Sci. 2014. N 49. P. $3268-3275$. DOI: $10.1007 / \mathrm{s} 10853-014-$ 8032-7

[7] Анненков Ю.М., Акарачкин С.А., Ивашутенко А.С. // Бутлеровские сообщения. 2012. Т. 31. № 9. С. 130-137.

[8] Suárez M., Fernandez A., Menendez J.L. et al. // Sintering Applications. InTech. Rijeka. 2013. P. 320-338. DOI: $10.5772 / 53706$

[9] Olevsky E., Froyen L. // Scripta Materialia. 2006. N 55. P. $1175-1178$.

[10] Olevsky E., Tikare V., Garino T. // J. Amer. Ceram. Soc. 2006. N 89 (6). P. 1914-1922.

[11] Olevsky E.A., Garcia-Cardona C. et al. // J. Am. Ceram. Soc. 2012. N 95 (8). P. 2414-2422.

[12] Елецкий А.В. // УФН. 2009. № 179 (3). С. 225-242.

[13] Muratov V.B. Vasil'ev O.O. et al. // J. Superhard Mater. 2012. Vol. 34. N 3. P. 173-178. 